\title{
PHÂN TÍCH Cơ CẤU THUỐC SỬ DUNG TẠI TRUNG TÂM Y TẾ HUYẾN GÒ CÔNG TÂY, TİNH TIỀN GIANG NĂM 2019
}

\author{
Nguyễn Đức Trung1, Nguyễn Hồng Châu ${ }^{2}$, Nguyễn Thị Thanh Hương²
}

\section{TÓM TẮT}

Đă̆t vấn đề: Cơ cấu các thuốc sử dụng tại cơ sở y tế phả̉n ánh một số bất cập liên quan đến sử dụng thuốc giúp nhà quản lý có các giải pháp quản lý các hoạt động mua sắm và kê đớn thuốc ngày càng hợp lý hơn. Mục tiêu của nghiên cứu là mô tả cơ cấu thuốc sử dụng theo một số chỉ số và theo phương pháp $A B C$, VEN. Đối tượng và phương pháp: 442 khoản mục thuốc được xuất kho tại khoa dược năm 2019 tại Trung tâm y tế huyện Gò Công Tây, tỉnh Tiền Giang. Phương pháp nghiên cứu: mô tả cắt ngang. Kết quả: 442 khoản mục thuốc tương ứng 8,567 tỷ đồng. Thuốc hóa dược sử dụng 391 khoản $(88,47 \%)$ với giá trị 7,149 tỷ đồng $(83,46 \%)$. Thuốc sản xuất trong nước sử dụng 357 khoản $(80,76 \%)$ với giá trị 6,863 tỳ đồng $(80,11 \%)$. Thuốc đường uống sử dụng 318 khoản (71,94\%) với giá trị 6,853 tỷ đồng (79,99\%). Mười nhóm thuốc có giá tri sử dung cao nhất (tổng giá trị 7,306 tỷ đồng) chiếm 85,29\% giá trị với 307 khoản; 24 nhóm thuốc còn lai chỉ chiếm $14,71 \%$ giá trị. Cớ cấu các thuốc sử dụng theo phân hạng $A B C$ về tỳ lê khoản muc: hạng $A$ chiếm $20,13 \%$; hang $B$ chiếm 26,01\%; hạng $C$ chiếm $53,86 \%$. Thuốc nhóm AN chiếm $22,47 \%$ giá tri; $6,56 \%$ khoản mục. Một số thuốc có cùng hoạt chất, hàm lượng, dạng bào chế được sử dụng ở cá hạng $A$ và hạng $B$. Kết luâan: $C o ̛$ cấu thuốc sử dụng tại Trung tâm y tế huyện Gồ Công Tây, tỉnh Tiền Giang năm 2019 còn chưa hợp lý trong sử dụng các nhóm thuốc chế phẩm y học cổ truyên; khoáng chất và vitamin. Cơ cấu thuốc mua sắm còn dàn trải. Thuốc không thiết yếu (thuốc N) được sử dụng nhiều.

\section{SUMMARY \\ AN ANALYSIS ON THE DRUG USE OF GO CONG TAY DISTRICT'S HEALTH CENTER, TIEN GIANG PROVINCE IN 2019}

Background and Objectives: Druq use analysis of a health center could provide insights into inappropriate druq use of the center, supporting health service providers in manaqing druq descriptions and druq purchasing. The main objective of the study is to describe the druq use distribution of Go Conq Tay health center in Tien Gianq province. Methods: This is a cross-sectional study which included 442 druq items distributed by the Department of pharmacy in the center in 2019. The study utilized ABC and VEN

${ }^{1}$ Bệnh viện trung ương quân đội 108

${ }^{2}$ Trung tâm y tể huyện Gò Công Tây, tỉnh Tiền Giang

${ }^{3}$ Trường Đại hoc Dước Hà Nội

Chịu trách nhiệm chính: Nguyễn Đức Trung

Email: ductrung108@gmail.com

Ngày nhận bài: 16.12 .2020

Ngày phản biên khoa họ: 22.01 .2021

Ngày duyệt bải: 8.2.2021 methods to analyze the data. Results: These 442 items were equivalent to 8.567 billion VND. 391 items used $(88.47 \%)$ were chemical synthesis drugs, accounting for 7.149 billion VND (83.4\% total drugs expenditure). Total number of domestic drug items was 357 items $(80.76 \%)$ and valued 6.863 billion VND (80.11\% total). As for drug administration route, oral drugs were used the most, with 318 counts (71.94\%) and equivalent to 6.853 billion VND (79.99\%). There were ten drug groups that were used the most (307 counts), responsible for the majority of total drug expenditure (7.306 billion VND, 85.29\%), other 24 drug groups were responsible for the remaining $14.71 \%$ of drug expense. Drug use distribution based on $A B C$ ranking were: $20.13 \%$ for rank $A, 26.01 \%$ for rank $B$ and $53.86 \%$ for rank C. AN drug group had $22.47 \%$ of total value, accounting for $6.56 \%$ of total number of items used. Similar active substances, dose and dosage form drugs were seen in both rank $A$ and $B$. Conclusions: The structure of drugs used at Go Cong Tay district's health center, Tien Giang province in 2019 was still irrational in the use of traditional medicine, minerals and vitamins drug groups. The structure of drug procurement was still scattered. Non-essential druqs (druq $\mathrm{N}$ ) were frequently used.

Keywords: drug list use, ABC, VEN, Tien Giang province, Vietnam

\section{I. ĐĂT VẤN ĐỀ}

Quản lý sử dụng thuốc hợp lý tại cơ sở y tế luôn được quan tâm bởi các nhà quản lý, để tăng cường hiệu quả công tác quản lý sử dụng thuốc, Bộ y tế đã ban hành nhiêuu văn bản quy định và hướng dẫn triển khai các hoạt động của Hội đồng thuốc và điều trị; khoa Dược bệnh viện. Thông tư số 21 năm 2013 quy định chức năng, nhiệm vụ của Hội đồng thuốc và điều trị, trong đó có nhiệm vụ phân tích các vấn đề liên quan đến sử dụng thuốc ${ }^{[1]}$. Có một số phương pháp được sử dụng trong đánh giá sử dụng thuốc đã được khuyến cáo và áp dụng tại các cơ sở y tế như phương pháp phân tích $A B C$, VEN danh mục thuốc sử dụng ${ }^{[1][4]}$. Ma trận $A B C / V E N$ cho thấy những thuốc cần quản lý chặt chẽ hơn đặc biệt là các thuốc hạng $A$, thuốc thuộc phân nhóm AN.

Trung tâm y tế huyện Gò Công Tây, tỉnh Tiền Giang là Trung tâm y tế đa chức năng có chức năng của bệnh viện hạng III với 110 giường bệnh. Năm 2019 mồ hình bệnh tật tại Trung tâm gồm 21 chương bệnh theo phân loại bệnh tật ICDX với 204.264 lượt khám và điều trị. Bệnh hệ tuần hoàn chiếm cao nhất $(22,2 \%)$, bệnh hệ tiêu 
hóa chiếm 20,21\%, bênh hê hô hấp chiếm $12,55 \%$, bệnh nội tiết, dinh dưỡng và chuyển hóa chiếm 7,46\%. Hàng năm tổng chi cho hoạt động thường xuyên tại Trung tâm khoảng 23 tỷ đồng, năm 2019 tổng tiền thuốc chiếm 36,89\% tổng chi thường xuyên của Trung tâm. Phân tích cơ cấu thuốc sử dụng tại Trung tâm năm 2019 nhằm mục tiêu mô tả cơ cấu thuốc đã sử dụng và tìm ra những vấn đề chưa hợp lý trong cơ cấu làm cơ sở cho việc đề xuất các giải pháp tăng cường quản lý sử dụng thuốc hợp lý tại Trung tâm trong những năm tiếp theo.

\section{II. ĐỐI TƯợNG VÀ PHƯƠNG PHÁP NGHIÊN CỨU}

2.1 Đối tượng nghiên cứu. Toàn bộ thuốc đã sử dụng từ 1/1/2019 đến 31/12/2019 gồm 442 khoản mục thuốc tại Trung tâm y tế huyện Gò Công Tây, tỉnh Tiền Giang.

2.2. Phương pháp nghiên cứu: Mô tả cắt ngang sử dụng số liệu hồi cứu

\section{KẾT QUẢ NGHIÊN CỨU}

3.1. Cơ câu danh mục thuốc sử dụng tại Trung tâm y tế huyện Gò Công Tây năm 2019.

Bảng 3.1. Tỷ lê khoản muc và giá trị thuốc sử dung

\begin{tabular}{|c|c|c|c|c|c|}
\hline $\mathbf{T T}$ & Nội dung & Số khoản & \% khoản & Giá trị (1000 đ) & \% giá trị \\
\hline \multicolumn{7}{|c|}{ Nhóm thuốc } \\
\hline 1 & Thuốc hóa dược & 391 & 88,47 & 7.149 .808 & 83,46 \\
\hline 2 & Chế phấm YHCT & 51 & 11,53 & 1.417 .620 & 16,54 \\
\hline \multicolumn{7}{|c|}{ Nguồn gốc xuất xứ } \\
\hline 1 & Thuốc sản xuất trong nước & 357 & 80,76 & 6.863 .805 & 80,11 \\
\hline 2 & Thuốc nhập khẩu & 85 & 19,24 & 1.703 .624 & 19,89 \\
\hline \multicolumn{7}{|c|}{ Đường dùng } \\
\hline 1 & Đường uống & 318 & 71,94 & 6.853 .078 & 79,99 \\
\hline 2 & Đường tiêm, truyền & 89 & 20,13 & 1.377 .103 & 16,07 \\
\hline 3 & Đường khác & 35 & 7,93 & 337.248 & 3,94 \\
\hline \multicolumn{7}{|c|}{ Tống } & $\mathbf{4 4 2}$ & $\mathbf{1 0 0}$ & $\mathbf{8 . 5 6 7 . 4 2 9}$ & $\mathbf{1 0 0}$ \\
\hline
\end{tabular}

Năm 2019, Trung tâm y tế huyện Gò Công Tây, tỉnh Tiền Giang đã sử dụng khoảng 8,57 tỷ đồng tiền thuốc của 442 khoản mục, trong đó thuốc hóa dược chiếm $83,46 \%$ giá trị, thuốc sản xuất trong nước chiếm 80,11\% giá trị, thuốc đường uống chiếm 79,99\% giá trị.

3.2. Cơ câu thuốc sử dụng theo nhóm tác dụng.

Bảng 3.2: Tỷ lệ khoản mục và giá trị thuốc sử dụng theo nhóm tác dụng

\begin{tabular}{|c|c|c|c|c|c|}
\hline TT & Nội dung & Số khoản & \% khoản & Giá trị (1000 đ) & \% giá trị \\
\hline 1 & Mười nhóm thuốc, trong đó: & 307 & 69,46 & 7.306 .543 & 85,29 \\
\hline 1.1 & Thuốc đường tiêu hóa & 50 & 11,31 & 1.351 .024 & 15,77 \\
\hline 1.2 & $\begin{array}{c}\text { Thuốc điều trị ký sinh trùng, chống } \\
\text { sốt rét }\end{array}$ & 70 & 15,84 & 1.326 .456 & 15,48 \\
\hline 1.3 & Thuốc tim mạch & 58 & 13,12 & 1.087 .781 & 12,70 \\
\hline 1.4 & $\begin{array}{c}\text { Hocmon và các chất tác đô̂ng vào hệ } \\
\text { thống nội tiết }\end{array}$ & 28 & 6,34 & 958.660 & 11,19 \\
\hline 1.5 & Nhóm thuốc khu phong trừ thấp & 17 & 3,85 & 637.722 & 7,44 \\
\hline 1.6 & Thuốc tác dụng trên đương hô hấp & 26 & 5,88 & 458.830 & 5,36 \\
\hline 1.7 & $\begin{array}{c}\text { Nhóm thuốc thanh nhiêt, giải độc, } \\
\text { tiêu ban, lợi thưy }\end{array}$ & 13 & 2,94 & 431.796 & 5,04 \\
\hline 1.8 & Thuốc giảm đau, hạ sốt; chống viêm & 27 & 6,11 & 395.767 & 4,62 \\
\hline
\end{tabular}




\begin{tabular}{|c|c|c|c|c|c|}
\hline & không steroid & & & & \\
\hline 1.9 & Khoáng chất và vitamin & 16 & 3,62 & 334.864 & 3,91 \\
\hline 1.10 & Thuốc tác dụng đường tiết niệu & 2 & 0,45 & 323.643 & 3,78 \\
\hline 2 & 24 nhóm còn lại & 135 & 30,54 & 1.260 .886 & 14,71 \\
\hline & Tống & $\mathbf{4 4 2}$ & $\mathbf{1 0 0}$ & $\mathbf{8 . 5 6 7 . 4 2 9}$ & $\mathbf{1 0 0}$ \\
\hline
\end{tabular}

Năm 2019, Trung tâm y tế huyện Gò Công Tây sử dụng 34 nhóm tác dụng của thuốc, mười nhóm có giá trị sử dụng cao nhất chiếm $85,29 \%$ giá trị tương ứng 69,46\% khoản mục thuốc. Trong mười nhóm này có 2 nhóm thuốc y học cổ truyền là Nhóm thuốc khu phong trừ thấp và nhóm thuốc thanh nhiệt, giải độc, tiêu ban, lợi thủy. Ngoài hai nhóm thuốc đặc trưng cho các Trung tâm y tế tuyến huyện gồm: thuốc tim mạch và hocmon và các chất tác động vào hệ thống nội tiết, Trung tâm y tế huyện Gò Công Tây còn sử dụng nhiều các thuốc đường tiêu hóa (chiếm $15,77 \%$ giá trị sử dụng) và nhóm thuốc kháng sinh (chiếm 15,48\% giá trị sử dụng). Nhóm thuốc giảm đau, hạ sốt; chống viêm không steroid và nhóm khoáng chất và vitamin có tỷ trong giá trị sử dụng tương ứng là $4,62 \%$ và $3,91 \%$ cho thấy cần lưu ý để tránh lạm dụng các nhóm thuốc này khi sử dụng.

\subsection{Cơ cấu danh mục thuốc sử dụng theo phân tích ABC/VEN}

Bảng 3.3: Tỷ lệ khoản mục và giá trị mỗi nhóm $V, E, N$ trong hạng $A, B, C$

\begin{tabular}{|c|c|c|c|c|c|}
\hline Hạng & Nộ́i dung & $\mathbf{V}$ & $\mathbf{E}$ & $\mathbf{N}$ & Tống \\
\hline \multirow{4}{*}{ A } & Số khoản & 10 & 50 & 29 & 89 \\
\cline { 2 - 6 } & \% khoản mục & 2,26 & 11,31 & 6,56 & 20,13 \\
\cline { 2 - 6 } & Giá trị (1000 đ) & 466.638 & 4.440 .637 & 1.925 .675 & 6.832 .951 \\
\cline { 2 - 6 } & \% giá trị & 5,44 & 51,83 & 22,47 & 79,75 \\
\hline \multirow{4}{*}{ B } & Số khoản & 7 & 75 & 33 & 115 \\
\cline { 2 - 6 } & \% khoản mục & 1,58 & 16,96 & 7,46 & 26,01 \\
\cline { 2 - 6 } & Giá trị (1000 đ) & 91.929 & 832.324 & 380.053 & 1.304 .306 \\
\cline { 2 - 6 } & \% giá trị & 1,07 & 9,71 & 4,44 & 15,22 \\
\hline \multirow{4}{*}{ C } & Số khoản & 29 & 184 & 25 & 238 \\
\cline { 2 - 6 } & \% khoản mục & 6,56 & 41,62 & 5,66 & 53,86 \\
\cline { 2 - 6 } & Giá trị (1000 đ) & 30.309 & 342.614 & 57.247 & 430.171 \\
\cline { 2 - 6 } & \% giá trị & 0,36 & 4,00 & 0,67 & 5,03 \\
\hline \multirow{3}{*}{ Tổng } & Số khoản & 46 & 309 & 87 & 442 \\
\cline { 2 - 6 } & \% khoản mục & 10,40 & 69,90 & 19,68 & 100,00 \\
\cline { 2 - 6 } & Giá trị (1000 đ) & 588.876 & 5.615 .576 & 2.362 .975 & 8.567 .429 \\
\cline { 2 - 6 } & \% giá trị & 6,87 & 65,55 & 27,58 & 100,00 \\
\hline
\end{tabular}

Kết quả phân tích $A B C$ danh mục thuốc sử tâm còn sử dụng nhiều thuốc nhóm $\mathrm{N}$, mặc dù dụng tại Trung tâm y tế huyện Gò Công Tây, tỉnh Tiển Giang năm 2019 cho thấy tính chưa hợp lý trong mua sắm tại Trung tâm được thể hiện qua tỷ lệ về khoản mục các hạng $A, B, C$ chưa phù hợp với khuyến cáo. Tỷ lệ khoản mục hạng $A$ chiếm 20,13\% (cao hơn 20\%), hạng B chiếm $26,01 \%$ (cao hơn $20 \%$ ) và hạng $C$ chiếm $53,86 \%$ (nhỏ hơn $60 \%$ ) cho thấy sự dàn trải trong mua sắm thuốc.

Ma trận $A B C / V E N$ bước đầu cho thấy Trung việc phân loại VEN tại Trung tâm hiện do dược sĩ tự phân loại nên chỉ mang tính tham khảo, tuy nhiên điều này cũng giúp cho Trung tâm rà soát lại việc sử dụng một số thuốc nhóm N. Phân nhóm AN gồm 29 khoản với giá trị chiếm $22,47 \%$ trong đó bao gồm nhiều thuốc chế phẩm y học cổ truyền.

3.4. Danh mục các thuốc được sử dụng ở cả hạng $A$ và $B$ (cùng hoạt chất, hàm lượng, dạng bào chế)

Bảng 3.4. Các thuốc cùng hoạt chât, hàm lượng, dạng bào chế được sử dụng ở cả hạng A và hạng B

\begin{tabular}{|c|c|c|c|c|c|c|c|}
\hline Tा & $\begin{array}{l}\text { Hoạt chất, dạng } \\
\text { bào chế, hàm lượng }\end{array}$ & Hạng & Tên thuốc & $\begin{array}{l}\text { Đơn v } \\
\text { tính }\end{array}$ & $\begin{array}{c}\text { Số lượng sủ } \\
\text { dựng }\end{array}$ & $\begin{array}{l}\text { Đơn giá } \\
\text { (VNĐ) }\end{array}$ & $\begin{array}{l}\text { Thành tiền } \\
\text { (VND) }\end{array}$ \\
\hline 1 & \multirow{2}{*}{$\begin{array}{l}\text { Cefotaxim bột pha } \\
\text { tiêm } 1000 \mathrm{mg}\end{array}$} & A & & Lọ & & 24.000 & 53.880 .000 \\
\hline 2 & & B & & $\mathrm{L}$ & & & 769 \\
\hline 3 & \multirow{2}{*}{$\begin{array}{l}\text { Diosmin + Hesperidin, } \\
\text { viên nén bao phim }\end{array}$} & A & & Viền & & & 68.956 \\
\hline 4 & & $B$ & SaViDimin & & 9.398 & 1.200 & 11.277 .600 \\
\hline
\end{tabular}


VIETNAM MEDICAL JOURNAL N¹\&2 - FEBRUARY - 2021

\begin{tabular}{|c|c|c|c|c|c|c|c|}
\hline & $450 \mathrm{mg}+50 \mathrm{mg}$ & & & Viên & & & \\
\hline 5 & \multirow{2}{*}{$\begin{array}{l}\text { Metformin, viên nén } \\
\text { bao phim } 850 \mathrm{mg}\end{array}$} & A & Metformin 850 & Viên & 1.162 .803 & 200 & 232.560 .600 \\
\hline 6 & & B & Meglucon 850 & Viên & & 645 & \\
\hline 7 & \multirow{2}{*}{$\begin{array}{c}\text { Paracetamol, viên nén } \\
500 \mathrm{mg}\end{array}$} & A & & Viên & & 102 & 966 \\
\hline 8 & & $B$ & $\mathrm{SaViP}_{\mathrm{s}}$ & Viên & 38.084 & 280 & 10.663 .520 \\
\hline 9 & \multirow{2}{*}{$\begin{array}{c}\text { Tobramycin, Dung } \\
\text { dịch tiêm } 80 \mathrm{mg} / 2 \mathrm{ml}\end{array}$} & $\mathrm{A}$ & Medphatobra 80 & Ōng & 772 & 49.500 & 38.214 .000 \\
\hline 10 & & B & $\begin{array}{c}\text { A.T } \\
\text { Tobramycine inj }\end{array}$ & Ống & 1.948 & 6.720 & 13.090 .560 \\
\hline
\end{tabular}

Có 10 thuốc của 5 hoạt chất được sử dụng đồng thời cả hạng $A$ và hạng $B$ (cùng hoạt chất, dạng bào chế và hàm lượng). Khi có 1 hoạt chất, 1 hàm lượng và 1 dạng bào chế được sử dụng dưới dạng 2 thuốc thì thuốc nào có giá rẻ hơn sẽ được sử dụng nhiều hơn. Ví dụ như: diosmin + hesperidin, viên nén bao phim 450mg $+50 \mathrm{mg}$ được sử dụng dưới dang 2 thuốc là Dacolfort và SaViDimin, song do giá của SaViDimin cao hơn so với Dacolfort, thực tế số lượng sử dụng Dacolfort 76.684 viên cao hơn rất nhiều hơn so với SaViDimin sử dụng 9398 viên. Tương tự đối với metformin, viển nén bao phim $850 \mathrm{mg}$; paracetamol, viên nén $500 \mathrm{mg}$; tobramycin, dung dịch tiêm $80 \mathrm{mg} / 2 \mathrm{ml}$. Riêng đối với cefotaxim bột pha tiêm 1000 mg được sử dụng với số lượng ít chênh lệch giữa 2 thuốc Taximmed và Taxibiotic 1000 (2245 lọ so với 2159 lọ), tuy nhiên do đơn giá của Taximmed cao gấp gần 3 lần so với Taxibiotic 1000. Vì vậy việc sử dụng 2 thuốc có cùng hoạt chất, hàm lượng, dạng bào chế ở cả 2 hạng $\mathrm{A}$ và $\mathrm{B}$ là tương đối hợp lý nhằm đảm bảo cung ứng đủ thuốc trong sử dụng khi sử dụng 2 thuốc có thể thay thế nhau khi cung ứng.

\section{BÀN LUÂ̂N}

Cơ cấu thuốc sử dụng tại Trung tâm y tế huyện Gò Công Tây, tỉnh Tiền Giang năm 2019 cho thấy Trung tâm sử dụng chủ yếu là thuốc hóa dược với tỷ lệ khoản mục là $88,47 \%$ tương ứng $83,46 \%$ giá trị. Với tỷ lệ này cho thấy Trung tâm còn sử dụng với tỷ lệ các thuốc là chế phẩm YHCT còn cao, cu thể là kết quả phân tích thuốc sử dụng theo nhóm tác dụng đã chỉ ra 2 trong số 10 nhóm tác dụng có giá trị sử dụng nhiều nhất là các thuốc chế phẩm YHCT như Thấp khớp Nam Dược, Khu phong hóa thấp Xuân Quang, Hoạt huyết dưỡng não, Diệp hạ châu, Kim tiền thảo... và đó cũng là các thuốc thuộc phận nhóm AN. Thực tế này cũng xảy ra tại một số bệnh viện hạng 3 khác khi cơ cấu mua sắm thuốc tại bệnh viện chưa hợp lý thông qua kết quả phân tích $A B C$ danh mục thuốc sử dụng. Đối với Trung tâm y tế huyện Gò Công Tây, việc mua sắm thuốc còn dàn trải thể hiện ở tỷ lệ $>20 \%$, điều này hoàn toàn ngược với bệnh viện đa khoa huyện Bát Xát, tỉnh Lào Cai thì việc mua sắm lại quá tập trung khi tỷ lệ khoản mục thuốc hạng $\mathrm{A}$ chỉ chiếm $8 \%{ }^{[3]}$.

Tỷ lệ khoản mục và giá trị các thuốc sử dụng có nguồn gốc sản xuất trong nước đều lớn hơon $80 \%$, Trung tâm sử dụng thuốc đường uống chiếm tỷ lệ cao (71,94\% khoản mục; 79,99\% giá trị) là phù hợp với một cơ sở y tế tuyến huyện với mô hình bệnh tật chiếm tỷ lệ cao là các bệnh hệ tuần hoàn, nội tiết dinh dưỡng, bệnh hệ hô hấp, phù hợp với tuyến y tế cơ sở quản lý trực tiếp các bệnh nhân mạn tính về huyết áp và đái tháo đường. Tuy nhiên việc sử dụng nhóm thuốc là các khoáng chất và vitamin với giá trị chiếm 3,91\% cũng cần được quan tâm trong giám sát sử dụng trong những năm tiếp theo. Một số vitamin thuộc phân nhóm AN như Magnes- B6, vitamin $B 1 \ldots$ cần cân nhắc kỹ khi kê đớn để tránh tình trạng bị từ chối thanh toán của cơ quan bảo hiểm xã hội. Và để công tác quản lý sử dụng thuốc được hiệu quả, hạn chế sử dụng thuốc nhóm AN rất cần thiết thống nhất phân loại các thuốc theo phân loại VEN phù hợp với mồ hình bệnh tật và hướng dẫn điều trị của Trung tâm. Việc phân loại VEN cần được thống nhất bởi Hội đồng thuốc và điều trị, được đơn vị thông qua làm cơ sở cho việc mua sắm và sử dụng ${ }^{[1][4]}$.

\section{KẾT LUÂN}

Năm 2019, Trung tâm y tế huyện Gò Công Tây, tỉnh Tiền Giang sử dụng 442 khoản mục thuốc với số tiền tương ứng 8,567 tỷ đồng. Nhóm thuốc hóa dược chiếm $88,47 \%$ khoản mục, $83,46 \%$ giá trị. Thuốc sản xuất trong nước chiếm $80,76 \%$ khoản mục, $80,11 \%$ giá trị. Thuốc đường uống chiếm $71,94 \%$ khoản mục, $79,99 \%$ giá trị. 5 nhóm thuốc có giá trị sử dụng cao nhất gồm: thuốc đường tiêu hóa, tim mạch, kháng sinh, hocmon và các chất tác động vào hệ thống nội tiết, khu phong trừ thấp. Tỷ lệ khoản mục các thuốc trong các hạng $A, B, C$ chưa hợp lý. Một số thuốc thuộc phân nhóm AN (29 thuốc) cần có biện pháp quản lý tốt hoạt động kê đơn.

TÀI LIỆU THAM KHẢO 
1. Bô Y tế (2013), Thôna tư $21 / 2013 / T T$-BYT nqày $8 / 8 / 2013$ Ouy đinh về tổ chức và hoat động của Hôi đồng Thuốc và điều trị trong bênh viên

2. Bộ Y tế (2018), Thông tư số $19 / 2018 / T T-B Y T$ ngày $30 / 8 / 2018$ Ban hành Danh mục thuốc thiết yếu

3. Nguyển Thị Thanh Hương, Hoàng Thị Nga (2020), Phẩn tích ma trận $A B C-V E N$ thuốc sử dung tại Bệnh viện huyện Bát Xát, tỉnh Lào Cai nẳm 2018, Tạp chí Dược học số 530, trang 11-14

4. Tổ chức Y Y tế Thế giới (2004), Hội đồng thuốc và điều trị - Cẩm nang hướng dẫn thực hành, trang 87-89,

5. WHO (2017); Model Lists of Essential Medicines (EML) $20^{\text {th }}$

\section{ĐÁNH GIÁ MỐI TƯƠNG QUAN GIỮA SỐ ĐO NHÃN ÁP CỦA NHÃN ÁP KẾ MACLAKOV VỚI NAK GOLDMANN VÀ NAK KHÔNG TIẾP XÚC}

\section{TÓM TẮT.}

Mục tiêu: Đánh giá mối tương quan giữa số đo nhãn áp của nhãn áp kế (NAK) Maclakov với NAK Goldmann và NAK không tiếp xúc. Đối tượng và phương pháp nghiên cứu: Nghiên cứu mố tả cắt ngang trên 702 mắt của 352 bệnh nhân khám và điều trị tại khoa Glôcôm Bệnh viện Mắt Trung ương từ tháng 11/2017 đến tháng 8/2018. Kết quả: Tương quan giữa kết quả đo của NAK Maclakov và Goldmann tương đối chặt chẽ với hệ số tương quan $r=0,937$; giá tri trung bình của sư khác nhau giữa 2 NAK là $2,014 \pm 2,562(p<0,001)$. Tương quan giữa kết quả đo của NAK Maclakov và NAK không tiếp xúc khá chă̆t chẽ với hệ số tương quan $r=0,875$; giá trị trung bình

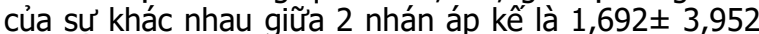
$(p<0,001)$. Nhãn áp đo được bằng NAK Goldmann và NAK không tiếp xúc có sư tương quan đồng biến, sư tương quan có ý nghĩa thống kề (hệ số tương quan $r$ $=0,915, p<0,001)$. Chênh lêch giứa nhãn áp khi đo bằng NAK Goldmann và khi đo bằng NAK không tiếp xúc trung bình là $-0,322 \mathrm{mmHg} \pm 2,937 \mathrm{mmHg}$. Tuy nhiên, kết quả đo giữa các loại NAK có biên độ, chiều khác biệt theo từng khoảng nhãn áp. Kết luận: NAK Goldmann và NAK không tiếp xúc có sự tương đồng cao với NAK Maclakov. Tuy nhiên biên độ và chiều của khác biệt lại phụ thuộc vào khoảng NA. Trong thực hành lâm sàng và nghiên cứu không thể qui đổi NA giữa các loại NAK.

Từ khóa: nhãn áp (NA), NAK Maclakov, NAK Goldmann, NAK không tiếp xúc, tương quan tuyến tính.

\section{SUMMARY}

\section{COMPARISON OF THREE METHODS OF} TONOMETRY: MACLAKOV TONOMETER, GOLDMANN APPLANATION TONOMETER AND NON- CONTACT AIRPUFF TONOMETER

Purpose: To analyze the correlation of Maclakov tonometer, Goldmann applanation tonometer (GAT)

${ }^{1}$ Bệnh Viện Mắt Trung Uơng

${ }^{2}$ Đại Hoc Y Hà Nôi

${ }^{3}$ Bệnh Viện Thanh Nhàn

Chiu trách nhiệm chính: Đỗ Tấn

Email: dotan20042005@yahoo.com

Ngày nhận bài: 21.12.2020

Ngày phản biên khoa học: 25.01.2021

Ngày duyệt bài: 10.2.2021

\section{ỗ Tấn ${ }^{1}$, Phạm Thị Thu Thủy ${ }^{2}$, Hoàng Thị lành ${ }^{3}$}

and non-contact airpuff tonometer results. Subjects and methods: Cross sectional study over 702 eyes of 352 patients who were treated at Glaucoma Deparment, Vietnam National institute of Ophthamology (VNIO) from November 2017 to August 2018. Results: A strongr positive correlation between Maclakov and GAT was found $(r=0.937, p<0.001 ; r=$, respectively). The mean difference between 2 tonometers was 2,014 $\pm 2,562 \mathrm{mmHg}(p<0.001)$. similarly, there was a strong positive correlation between Maclakov and Noncontact airpuff tonometer $r=0.875, p<0.001$ with the mean difference of $1,692 \pm 3,952 \mathrm{mmHg}$. There was also a strong positive correlation between GAT and airpuff tonometer $(r=0.915, p<0.001)$. The mean difference was $0,322 \mathrm{mmHg} \pm 2,937 \mathrm{mmHg}$. However, the magnitude of way of difference varied depending on the IOP intervals. Conclusions: Three tonometers have a good agreement from one to another. However, their readings are very different depending upon different IOP intervals. IOP readings from these 3 tonometers were not inerchangable.

Keywords: intraocular, Maclakov tonometer, Goldmann applanation tonometer, non-contact airpuff tonometer.

\section{I. ĐẶT VẤN ĐỀ}

NAK là dụng cụ đo áp lực nội nhãn một cách gián tiếp. Tùy theo sự thay đổi hình dạng giác mạc khi đo, người ta chia ra 2 loại NAK: loại ấn Iõm và loại đè phẳng. NAK đè phẳng gồm hai loại: loại có lực ép cố định như NAK Maclakov và loại có diện tích vùng đè phẳng cố định như NAK Goldmann và hơi [1]. 3 loại NAK hay sử dụng trên lâm sàng và nghiên cứu tại Việt Nam là NAK Maclakov, NAK Goldmann và NAK không tiếp xúc (phụ hơi).

NAK Maclakov ra đời và sử dụng từ năm 1885 với ưu điểm là gọn, dễ sử dụng, rẻ tiền và kết quả có thể lưu lại, được sử dụng rộng rãi trong các cơ sở y tế của ở miền Bắc nước ta. NAK Goldmann được ra đời và sử dụng từ năm 1954, kết quả đo được thường chính xác và được xem như tiêu chuẩn vàng trong đo nhãn áp. NAK không tiếp xúc được sử dụng rộng rãi trên thế giới từ năm 1972 với ưu điểm là chính xác, dễ 